\title{
Modification of concentration-response curves to inhaled methacholine after the pollen season in subjects with pollen induced rhinitis
}

\author{
L Prieto, M López, J M Bertó, A Peris
}

\begin{abstract}
Background - The effect of cessation of exposure to pollen on the concentrationresponse curves to inhaled methacholine was investigated.

Methods - Methacholine inhalation challenges (up to $200 \mathrm{mg} / \mathrm{ml}$ ) were performed in 13 non-asthmatic patients with grass and/or Parietaria pollen-induced rhinitis during the pollen season, and one and four months after it. Concentrationresponse curves were characterised by their $\mathbf{P C}_{20}$, position, and plateau.

Results - Geometric mean methacholine $\mathrm{PC}_{20}$ increased from $6.4 \mathrm{mg} / \mathrm{ml}$ during the pollen season to $28 \cdot 2 \mathrm{mg} / \mathrm{ml}$ and $54.9 \mathrm{mg} / \mathrm{ml}$ one and four months after the end of season, respectively. The mean (SE) level of the plateau decreased from $30.5(4.3) \%$ in the pollen season to 23.3 $(3.7) \%$ and $20.1(3.3) \%$ one and four months after the end of pollen season, respectively. Although the methacholine concentration that produced $50 \%$ of the maximal response increased from $2.9 \mathrm{mg} / \mathrm{ml}$ to $4.3 \mathrm{mg} / \mathrm{ml}$ and $6.0 \mathrm{mg} / \mathrm{ml}$, the differences were not significant.

Conclusions - In non-asthmatic patients with pollen-induced rhinitis cessation of exposure to pollen is associated with significant modifications in the methacholine threshold value and level of plateau, and with a small shift in the concentration-response curves to the right.
\end{abstract}

(Thorax 1994;49:711-713)

Previous studies in non-asthmatic subjects with allergic rhinitis have shown decrements in the provocative concentration of methacholine producing a $20 \%$ fall in $\mathrm{FEV}_{1}\left(\mathrm{PC}_{20}\right)$ related to natural allergen exposure. ${ }^{1}$ Other features of the dose-response curve, such as the position and level of plateau, may also be important in characterising the response to methacholine. ${ }^{2}$ We have therefore examined the effect of cessation of exposure to pollen on $\mathrm{PC}_{20}$, position, and the maximal response of concentration-response curves to methacholine in non-asthmatic patients with pollen sensitive allergic rhinitis.

\section{Methods}

Thirteen non-smoking patients (eight men; mean age 38 (range 22-59) years) with seasonal allergic rhinitis were studied. Criteria for inclusion were age 18 years or over; a positive skin prick test (weal diameter $\geqslant 3 \mathrm{~mm}$ compared with negative control) to grass and/or Parietaria pollens; no skin sensitisation to other allergens (olive, house dust mites, Alternaria, Aspergillus, Neurospora, Penicillium, Cladosporium, and cat and dog dander); no previous history of dyspnoea, cough, wheeze or exercise-induced asthma; no respiratory infections during the four weeks before each methacholine challenge.

Three methacholine inhalation challenges were performed: (1) in the middle of the grass and Parietaria pollen season; (2) one month after the end of the pollen season; and (3) four months after the end of the pollen season.

Each patient was required to have an $\mathrm{FEV}_{1}$ (three measurements that agreed within $5 \%$ ) of at least $80 \%$ of the predicted value. ${ }^{3}$ Spirometric testing was performed on a dry rolling seal spirometer (Model PFT Horizon System Two; Sensormedics, California, USA). Antihistamines were withheld for at least 72 hours. No other medication was taken during the study except at the peak of symptoms where intranasal beclomethasone dipropionate or budesonide was used by one and two subjects, respectively.

Methacholine challenge tests $^{4}$ were performed with a Hudson 1720 nebuliser (Temecula, California, USA). The mean (SD) output was $0.198(0.017) \mathrm{ml} / \mathrm{min}$. The nebuliser was connected directly to a mouthpiece and the aerosol was inhaled through the mouth by tidal breathing for two minutes. Phosphate buffered saline (PBS) was inhaled first, followed at intervals of 3.5-4 minutes by twofold increasing concentrations of methacholine (Sigma; St Louis, Missouri, USA) from 0.39 to $200 \mathrm{mg}$ / ml. $\mathrm{FEV}_{1}$ was measured 60-90 seconds after each inhalation. The challenge was extended until the $\mathrm{FEV}_{1}$ fell more than $50 \%$ from the post PBS value or the highest concentration of methacholine was reached.

Concentration-response curves were characterised by their $\mathrm{PC}_{20}$, position $\left(\mathrm{EC}_{50}\right)$, and maximal response plateau. The $\mathrm{PC}_{20}$ and $\mathrm{EC}_{50}$ (concentration of methacholine producing $50 \%$ of the maximal response) were obtained by linear interpolation. 
A plateau response was considered to be present when, for three or more of the highest concentrations of methacholine, the $\mathrm{FEV}_{1}$ did not change by more than $5 \%$. The level of the maximal response was obtained by averaging the data points on the plateau. ${ }^{5}$

Grass and Parietaria pollen counts were recorded daily with a Burkard spore trap (Burkard, Herts, UK) and expressed as the mean count $/ \mathrm{m}^{3}$ of air each week.

The study was approved by the hospital medical ethics committee and all patients gave informed consent.

\section{STATISTICAL ANALYSIS}

All $\mathrm{PC}_{20}$ and $\mathrm{EC}_{50}$ values were log transformed before analysis and $\mathrm{PC}_{20}$ values $>200 \mathrm{mg} / \mathrm{ml}$ were assigned to 200 . In two subjects who showed $\mathrm{FEV}_{1}$ falls $>50 \%$ without evidence of plateau during the pollen season the plateau levels were assigned as the percentage decline in $\mathrm{FEV}_{1}$ at the end of the protocol.

The results of prechallenge $\mathrm{FEV}_{1}, \mathrm{PC}_{20}$, $\mathrm{EC}_{50}$, and plateau level in each period were compared by analysis of variance of repeated measurements. Data are mean (SE) unless otherwise stated; $p$ values $<0.5$ are considered significant.

\section{Results}

Weekly grass pollen counts between 35 and 268 grains $/ \mathrm{m}^{3}$ were recorded from May to July, and weekly Parietaria pollen counts between 145 and 327 grains $/ \mathrm{m}^{3}$ were recorded from the end of April to the beginning of August.

Baseline $\mathrm{FEV}_{1}$ values during the pollen season, one month, and four months afterwards were $3.7(0.3) 1,3.7(0.3) 1$, and $3.6(0.3) 1$, respectively. Two subjects (table) had $\mathrm{PC}_{20}$ values $>200 \mathrm{mg} / \mathrm{ml}$ throughout the three periods. In the remaining 11 subjects the geometric mean methacholine $\mathrm{PC}_{20}$ increased sig-

$P C_{20}$ and plateau values during the pollen season and one and four months after

\begin{tabular}{|c|c|c|c|c|c|c|}
\hline \multirow{2}{*}{$\begin{array}{l}\text { Patient } \\
\text { no. }\end{array}$} & \multicolumn{3}{|c|}{$P C_{20}(m g / m l)$} & \multicolumn{3}{|c|}{ Plateau level (\%) } \\
\hline & $\begin{array}{l}\text { Pollen } \\
\text { season }\end{array}$ & $\begin{array}{l}\text { One } \\
\text { month } \\
\text { after }\end{array}$ & $\begin{array}{l}\text { Four } \\
\text { months } \\
\text { after }\end{array}$ & $\begin{array}{l}\text { Pollen } \\
\text { seaon }\end{array}$ & $\begin{array}{l}\text { One } \\
\text { month } \\
\text { after }\end{array}$ & $\begin{array}{l}\text { Four } \\
\text { months } \\
\text { after }\end{array}$ \\
\hline $\begin{array}{r}1 \\
2 \\
3 \\
4 \\
5 \\
6 \\
7 \\
8 \\
9 \\
10 \\
11 \\
12 \\
13\end{array}$ & $\begin{array}{c}200 \\
2.9 \\
1.1 \\
200 \\
1.6 \\
200 \\
10.4 \\
100 \cdot 0 \\
4.4 \\
1.2 \\
23.7 \\
1.3 \\
4.8\end{array}$ & $\begin{array}{c}200 \\
8 \cdot 1 \\
2 \cdot 4 \\
200 \\
200 \\
48 \cdot 1 \\
200 \\
200 \\
52 \cdot 6 \\
3 \cdot 8 \\
200 \\
9 \cdot 9 \\
3 \cdot 3\end{array}$ & $\begin{array}{c}200 \\
191 \cdot 0 \\
3 \cdot 0 \\
200 \\
200 \\
200 \\
200 \\
200 \\
144 \cdot 0 \\
7 \cdot 0 \\
200 \\
12 \cdot 1 \\
5.7\end{array}$ & $\begin{array}{c}9.5 \\
38 \cdot 0 \\
57 \cdot 3 \dagger \\
8.9 \\
29 \cdot 6 \\
16 \cdot 1 \\
23.5 \\
18 \cdot 6 \\
30 \cdot 7 \\
43.0 \\
25 \cdot 4 \\
50 \cdot 6 \dagger \\
46.0\end{array}$ & $\begin{array}{r}7 \cdot 2 \\
33 \cdot 7 \\
46 \cdot 6 \\
9 \cdot 7 \\
12 \cdot 2 \\
23 \cdot 6 \\
18 \cdot 3 \\
14 \cdot 8 \\
23 \cdot 6 \\
32 \cdot 0 \\
6 \cdot 9 \\
29 \cdot 1 \\
45 \cdot 0\end{array}$ & $\begin{array}{r}6.4 \\
19 \cdot 4 \\
40.2 \\
5.5 \\
15.8 \\
15.4 \\
17.8 \\
13.9 \\
19 \cdot 9 \\
29.5 \\
8.8 \\
25.4 \\
43.5\end{array}$ \\
\hline $\begin{array}{l}\text { GM } \\
\text { Mean } \\
\text { SE }\end{array}$ & $6 \cdot 4$ & $28 \cdot 2^{*}$ & $54 \cdot 9 * *$ & $\begin{array}{r}30 \cdot 5 \\
4 \cdot 3\end{array}$ & $\begin{array}{c}23 \cdot 3^{* *} \\
3 \cdot 7\end{array}$ & $\begin{array}{c}20 \cdot 1^{* *} \\
3.3\end{array}$ \\
\hline
\end{tabular}

$\mathrm{PC}_{20}=$ provocative concentration of methacholine producing a $20 \%$ fall in $\mathrm{FEV}_{1} ; \mathrm{GM}=\mathrm{geo}-$ one challenge.

one challenge.

t Plateau not detected. nificantly both one and four months after the pollen season. In subjects with no censored values in at least one challenge $\mathrm{PC}_{20}$ values one and four months after the pollen season were $2 \cdot 1(0.7)$ and $3.4(0.7)$ doubling concentrations higher than $\mathrm{PC}_{20}$ values during the pollen season. $\mathrm{PC}_{20}$ values four months after the pollen season were $1.5(0.6)$ doubling concentrations higher than $\mathrm{PC}_{20}$ values one month after the season.

The level of the maximal response decreased significantly after the pollen season, but the geometric mean (range) $\mathrm{EC}_{50}$ increased from $2.9(0.8-12.4) \mathrm{mg} / \mathrm{ml}$ during the pollen season to $4.3(1.3-11.9) \mathrm{mg} / \mathrm{ml}$ and $6.0(0.8-28.9) \mathrm{mg} /$ $\mathrm{ml}$ one and four months after it.

\section{Discussion}

The results of this study confirm that in nonasthmatic patients with pollen-induced rhinitis the cessation of exposure to pollen is associated with a significant increase in methacholine $\mathrm{PC}_{20}$, a decrease in the level of plateau, and a small shift in the concentration-response curves to the right.

The baseline $\mathrm{FEV}_{1}$ values in each period did not differ, and patients were sensitised to grass and/or Parietaria pollens but did not show skin sensitisation to other allergens. Nasal corticosteroids may have decreased $\mathrm{PC}_{20}$ values during the seasonal period in three patients, ${ }^{6}$ but this would have resulted in a smaller change in $P_{20}$ between seasonal and postseasonal periods in these subjects. We can therefore reasonably attribute changes in airway responsiveness to natural exposure to pollens.

Boulet et $a l^{1}$ showed that, in subjects with hay fever, natural pollen exposure significantly increased airway responsiveness (reduction of $P_{20}$ ) to methacholine and our results are in agreement with these observations. However, estimation of change in $\mathrm{PC}_{20}$ in non-asthmatic patients with allergic rhinitis is complicated because most subjects have $\mathrm{PC}_{20}$ values above the upper limit of measurement (seven of our 13 patients) and repeated measures provide no estimate of change. We have attempted to minimise the effect of censored values by including subjects in whom it was possible to obtain a measurement of $\mathrm{PC}_{20}$ in at least one challenge.

To accurately define the position of the concentration-response with respect to the $x$ axis a complete concentration-response curve must be performed. ${ }^{2}$ A plateau response must therefore be achieved so that an $\mathrm{EC}_{50}$ value can be assigned. To our knowledge this is the first study in which the effect of natural allergenic exposure on the plateau in response to methacholine has been investigated. Our results show that the level of the plateau decreases after the pollen season. Although a shift in the concentration-response curve to the right (increased $\mathrm{EC}_{50}$ ) was detected after the pollen season, this change was not significant.

Boonsawat et $a l^{7}$ observed that allergen inhalation in the laboratory increased the maximal response to methacholine in atopic sub- 
jects with asthma or allergic rhinitis. However, provocation with nebulised allergen extract is different from natural exposure to pollen grains. The results of our study show that in subjects with pollen-induced rhinitis the cessation of exposure to pollens is associated with a decrease in methacholine responsiveness.

We would like to thank the volunteers who kindly helped us with this study, Dr Alfonso Romar for statistical analyses, and Ms Maria José Pérez and Bertha Camps for technical assistance. Data of pollen counts were provided by $\mathrm{Dr}$ Luis Caballero.

1 Boulet LPh, Morin D, Milot J, Turcotte H. Bronchial responsiveness increases after seasonal antigen exposure in non-asthmatic subjects with pollen-induced rhinitis. Ann Allergy 1989;63:114-9.

2 Moreno RH, Hogg JC, Paré PD. Mechanics of airway narrowing. Am Rev Respir Dis 1986;133:1171-80.

3 Quanjer PhH (Ed). Standardized lung function testing. Bull Eur Physiopathol Respir 1983;19(suppl 5):1-95.

4 Cockcroft DW, Killian DN, Mellon JJA, Hargreave FE Bronchial reactivity to inhaled histamine: a method and clinical survey. Clin Allergy 1977;7:235-43.

5 Sterk PJ, Daniel EF, Zamel M, Hargreave FE. Limited bronchoconstriction to methacholine using partial flowvolume curves in nonasthmatic subjects. Am Rev Respir Dis 1985;132:272-7.

6 Aubier M, Levy J, Clerici Ch, Neukirch F, Herman D. Different effects of nasal and bronchial glucocorticosteroid administration on bronchial hyperresponsiveness in patients with allergic rhinitis. Am Rev Respir Dis patients with 6 .

7 Boonsawat W, Salome ChM, Woolcock AJ. Effect of allerBonsawat , Salome ChM, Woolcock AJ. Effect of allergen inhalation on the maximal response plateau of the
dose-response curve to methacholine. Am Rev Respir Dis 1992;146:565-9.
A system is said to be chaotic in a scientific sense when the initial conditions of that system cannot be defined. A system under these conditions will appear to obey physical and chemical laws during short term observations but, due to this initial uncertainty, the ultimate manifestations of manipulations of the system cannot be predicted with accuracy. The human body is such a system. Under most, if not all, clinical conditions it is impossible to describe with the necessary accuracy the initial state of health of the body prior to the onset of a disease process. Most studies, no matter how rigid the inclusion and exclusion criteria are, must therefore contain a random sampling of patients whose outward appearance may appear similar but whose initial conditions may be very different. The implications of this may be very far reaching.

Cellular and laboratory animal preparations have better potential for establishing more uniform initial biological conditions than clinical human experimentation. As a result it is more likely that these experiments would demonstrate treatment benefits since there are fewer outside influences on these more simple systems to effect outcome - that is, there is less chaos present. This in part may explain the disparate results seen in some cellular and animal models of treatment regimes when applied to human populations. However, they do represent the necessary first steps in establishing efficacy of novel therapies and, in fact, may eventually be used to help establish the minimal requirements necessary for truly matching the initial conditions of subjects undergoing human experimentation.

Chaos presents many difficult challenges for the clinical researcher. Under most circumstances the overt manifestations of a disease are preceded by a non-specific prodrome. At the time a diagnosis is established, therefore, the biological system has undergone numerous interactions which may vary immensely from subject to subject. The threshold for an individual to present for treatment varies considerably, making it difficult consistently to manipulate the system at the same time in the course of a disease. The consequence of this is to increase the chaos of the biological system. As the system deviates from its resting state in the course of these reactions, it may reach a point where the system can no longer be manipulated by the planned intervention. If enough subjects in a clinical study reach this point the intervention may be perceived from a statistical standpoint to have no benefit - that is, a false negative result.

Earlier identification of a potential subject with the specific clinical entity to be studied, accompanied by the exclusion or statistical separation of patients found later in the course of the disease, should in part reduce the effect of chaos on the outcome of the intervention. Much work is currently being conducted in this area and new earlier markers for ARDS and sepsis are presently being evaluated. Additional work needs to be done to determine how better to match the initial conditions of patients entered into a study. The relative importance of all the potential influences of other organ system deficits on outcomes needs to be determined, such as the patient's nutritional state, recent and remote infectious disease history, and medication history. Finally, the use of empiricism may be required until the above information is available. Under these constraints investigators may be forced to apply a proposed intervention to a large initial group of patients in whom an exhaustive database has been obtained. A detailed statistical evaluation might then demonstrate a subgroup of patients which appeared to have benefited from the intervention. The final step would be to apply the therapy again to this identified subgroup of patients in a randomised, prospective study which should then ultimately answer the question of efficacy. Although this could increase the cost and potentially slow down the process of clinical research, it would result in studies less confounded by chaos. The data from these studies would be less tainted with false positive and false negative results. 